\title{
Genetically modified organisms and sustainable crop production: A critical review
}

\author{
Lavlu Mozumdar ${ }^{1}$, Mohammad Amirul Islam ${ }^{2}$ and Sumitra Saha ${ }^{3}$ \\ ${ }^{1}$ Department of Rural Sociology, ${ }^{2}$ Department of Agricultural Statistics and ${ }^{3}$ Department of Biotechnology, \\ Bangladesh Agricultural University, Mymensingh-2202, Bangladesh. E-mail: lavlurs@yahoo.com
}

\begin{abstract}
Fighting against global hunger in the adverse climatic condition is a major concern of the governments around the globe. The pace of population growth is overwhelmingly defeating the growth in crop production. In this context, introduction of GMO is emerging as a probable solution for sustainable crop production. However, such developments are not beyond criticism. This paper assesses and evaluates the prospects and challenges of introduction of GMO in a global perspective. Experiences of GM crop cultivation in different countries are also considered. This paper is a review of all accessible literature on GMO and sustainable crop production. This review will give a flavor of the on going debate and help take decision by the interested countries regarding GMO adoption. Furthermore, on the basis of the review this paper suggests some policy recommendations.
\end{abstract}

Keywords: GMOs, Climate change, Global hunger; Sustainable crop production

\section{Introduction}

New technology can act as the driver of increasing resources and that can improve the human living conditions endlessly (Nyangel et al., 2011). The reality of technological revolution shows that technology creates the optimistic economic impacts in the society whereas new technology can push the socioeconomic development with a rising rate. If we analyze the different technological age, for instances, 7000 years of agrarian age while demonstration is seen as the key element; 350 years of industrial age when steam engine is considered as the core component; 50 years of information age where electricity and micro-processor is the most important instrument; and 25 years of bio-tech age while genetics may be the key governing matter of socioeconomic development of farmers. This is because new technology is related to scientific knowledge and that knowledge can be converted into products and processes for adjusting them to response in socioeconomic conditions (Juma, 2005).

The different generation of agronomic bio-tech traits may possibly be improved the quality of yield by the combination of traditional and advanced molecular genetics for instances the rare breed breeding of 1850s, hybridization and mutagenesis of 1920s and the genomics and GMOs (Genetically Modified Organisms) of 1990s. The technologies of 1920s wouldn't be able to feed the today's population, nor will today's feed 2050s. This is because the first generation agronomic traits are crop production and pest management and the second generation agronomic traits are crop yield and drought tolerance, whereas, the third generation traits are quality traits related to crop and animal productivity and human nutrition, and bio-materials related to bio-fuels and bio-pharma. Insect resistant and herbicide tolerance GM crops are in commercial application and other traits are in the pipeline of research.

Adoption of GM crop technology has increased quickly since 1990. Total area of GM crops has extended to 160 million hectares in 2011 from 1.7 million hectares in 1996 (Table 1). Globally, about 16.7 million farmers are growing GM crops in 29 countries. Nineteen developing countries are following GM crop technologies including three giants India, China and Brazil (James, 2011). It has already captured about $9 \%$ of the global arable land and the countries with the largest area of GM crop are the United States (50\%), Argentina (17\%), Brazil (13\%), Canada (6\%), India (6\%), and China (3\%) (James, 2009). Remarkably, Spain grows a significant level of GM crops in Europe. In such a way, applying biotechnologies as well as GMOs may perhaps provide opportunities for improving the economy of developing countries and the wellbeing of the people offering increased agricultural production, improved human health, and reduced environmental degradation (Nyangel et al., 2011). This paper critically discusses the opportunities and challenges of biotechnology as well as GMOs relating to sustainable development in crop production on the basis of available relevant review of literatures. 
Table 1. Total area of GM crops around the world

\begin{tabular}{|c|c|}
\hline Year & Hectares (million) \\
\hline 1996 & 1.7 \\
\hline 2001 & 52.6 \\
\hline 2006 & 102.0 \\
\hline 2007 & 114.3 \\
\hline 2008 & 125.0 \\
\hline 2009 & 134.0 \\
\hline 2010 & 148.0 \\
\hline 2011 & 160.0 \\
\hline
\end{tabular}

Source: James, 2011

\section{Prospects and challenges of GMOs: A critical discussion}

At first it is important to provide a fruitful answer of the question related to "Sustainable crop production: Why it is a matter in sustainable agriculture?". We are concerned that agriculture as well as sustainable crop production is at the heart of diverse global challenges more specifically for population and income growth, the impact of ecosystem and climate change, natural resource availability and global food security. Again it is not so easy to define 'sustainable agriculture' as it means different things to different people, for example, organic agriculture by Altieri (1995), food sovereignty movement by Shiva and Bedi (2002) and multifunctional agriculture by Huylenbroeck and Durand (2003). In this situation, there is an interesting debate about sustainable crop production through biotechnology as well as GMOs.

A common question we face frequently is that, what are the reasons behind global food crisis? It may be due to different reasons like demand for bio-fuel, population growth, global climatic changes, speculation of food products, low agricultural productivity and natural calamities. Reality shows that the global demand for five major crops like rice, wheat, soybean, cotton, and corn is increasing day by day. From that aspects farmers must have to be more productive and more resource efficient to meet the global food demand and in that case emphasis on breeding, improvements of agronomic practices and biotechnology can be the strategies that can maximize the yield grains or production. The potentiality of biotechnology as well as GM crops may be diversified, for instances, GM crops may improve the economics of production, significantly reduce the pollutions by destroying accumulated pollutants and may protect the environment, and can maintain the sustainable production of existing and new products (Gavrilescu and Chisti, 2005). On the other hand, a number of scholars (e.g., Losey et al., 1999; Altieri, 2001; Sharma, 2004; Friends of the Earth, 2008) disagree with the previous argument. Among them Altieri and Nicholls (2005) argue that GMOs aren't able to guarantee food security, protect the environment and reduce poverty in many developing countries but they don't have very specific reasons for their argument. We think that there may be three important challenges related to GMOs and sustainable agriculture specifically: i) producing more or maximizing production, ii) conserving more resources by reducing aggregate use of key resources of production and iii) improving the farmers standard of living by boosting productivity and efficiency through biotechnology and reaching them more than five million subsistence farmers around the world by 2030. The reason behind it is to consider the following three as the new vision of world agriculture more exclusively: i) to have access to sufficient nourishing, affordable food and other agricultural products to all people; ii) to managing and conserving environmental resources effectively, and iii) to consider agriculture as a major driver for sustainable economic growth and development around the world.

A quite number of potentialities of commercialized GM crops are observed in the last few years in different regions around the world. Brookes and Barfoot (2009) examine the impact of four GM crops such as soybean, corn, cotton, and canola on the production base and show that GM crops have made significant contribution in increasing the level of global production in these four crops, for example, 62 million tonnes and 68 million tonnes more respectively to global production of corn and soybean. It also examines the impact of these four crops on global farm income and indirect farm-level income and shows that at the farm level there are about US $\$ 10.1$ billion net economic benefit in 2007 and US $\$ 44.1$ billion 
for the 12-year period in nominal terms. It also shows the positive indirect benefit in farm level income in relation to the adoption of GM crop technology. Once more commercialized GM crops have reduced the impact of agriculture on biodiversity with the help of enhancing the practice of conservation tillage, reducing the use of insecticides and using more environment friendly herbicides, and increasing yields by reducing the pressure on land (Carpenter, 2011).

Control of weed has been a challenge throughout the history of agriculture. This is because weeds represent a significant threat to agricultural productivity and cause a serious loss in production even with control efforts. Prior to chemical herbicides; tillage and other mechanical methods have been used as primary tools of weed control. Extensive tillage is considered as a contributing factor to the dust bowl in the 1930s, which would lead to the movements of conservation tillage. Technological developments have increased the available tools for weed control, for example, invention of synthetic chemical herbicides in the 1950s and 1960s has offered growers a new set of tools for controlling weeds. Roundup and other broad spectrum of herbicides have also offered farmers a new burn-down tool for weeds. Moreover, biotechnology has provided additional tool to the producers in their quest to control weeds such as herbicides tolerant crops have enabled the farmers not to use wide ranges of herbicides in the crop field for a greater control of weed. Many producers have adopted these crops mainly due to several key benefits to their weed control system.

Genetically modified crop like HT soybean has brought several socio-economic benefits for the growers in Argentina along with the significant positive impact on the environment (Giuffre, 2006). Farmers have turned in the practice of no tillage of land for this crop and the practice has quickly expanded in many Latin American countries. Argentina is one of the leading countries where nineteen million hectares have cultivated under the no-till farming system (Micucci and Taboada, 2006). Though, the glyphosate use may increase in the crop field due to the no tillage of land in farming practices. Qaim and Traxler (2005) argue that the glyphosate use doesn't have harmful and negative effects on the environment. Glyphosate has no residual activity due to a low level of toxicity which is rapidly decomposed by soil microorganisms (Burachik, 2010). It has reduced the use of different herbicides which is environmentally harmful. Moreover, conservation tillage system has brought several benefits like reduced soil erosion, fuel savings, wildlife protection and reduced discharge of greenhouse gases.

The production of insect resistant BT cotton has remarkably reduced the insecticide use (Qaim, and De Janvry, 2005). In addition, yield may increase $30 \%$ in case of BT cotton and $17 \%$ for herbicide tolerant varieties. Similarly, the maize yield may increase from $5.5 \%$ to $9 \%$ for insect resistant varieties and from $3 \%$ to $22 \%$ for herbicide tolerant varieties depending on the regions and periods of production (Brookes and Barfoot, 2009). These increased yields may achieve with less amount of cultivated land along with improved conservation of soil and biodiversity, which is one of the most important contributions of GM crop technology. From that aspect, we may argue that commercialized GM crops can create a significant contribution to increase agricultural productivity in many developing regions.

Increased productivity in global agriculture is more important due to the nature of decreasing natural resource-base and to make sure the adequate availability of food for the growing population. From that point of view, GMOs can be considered as one of the helping hands to feed the 9 billion people in the near future by 2030 through increased agricultural productivity. New seed technologies have increased the rural farm income and reduced poverty in developing countries (Hazell and Ramasamy, 1991; Fan et al., 2005). These impacts are also expected for GM crops (FAO 2004). Moreover, nutritionally enhanced crops may possibly help in improving the health conditions of consumers (Bouis, 2007; Unnevehr et al., 2007). From that sense, it may be possible to pick up the standard of living in low income poor countries through GM crop technology as it can boost up the food production, improve nutritional quality and upgrade the health status of the consumers (Graff et al., 2006). Some researchers (Huang et al., 2005; Pray et al., 2002) argue that significant productivity gains and improvement of farm workers' health status have already been achieved with the help of GM crop technology, though it is an area of controversy. Moreover, genetic bio-fortification of food-crops might act as a biologically and economically useful approach to large scale alleviation of micronutrient deficiencies (Albrecht, 2002; Bouis, 2004). Qaim (2010) argue for the environmental benefits of GM crops. 
Instead of these above mentioned potentials, the uses of GM crop technology have faced a serious crisis in different regions of the world due to public media, trade regulations and overreach endeavor of antibiotech lobby groups (Pinstrup-Andersen and Schioler, 2001; Miller and Conko, 2004; Herring, 2007; Paarlberg, 2008). For instances, GMO is considered as the products of multinational companies. In that case, there is a big problem of intellectual property rights. This is because, farmers' perception that they don't want to consider their property rights to others as well as to some multinational companies. It can create them dependent to others for their production technologies especially for seeds. Again climate sensitivity in each and every country is also a major factor in the production of GM crops as GMOs are developed considering a particular environmental set-up (for example rainfall, temperature, moisture, soil quality etc.) which may vary across the country. In addition, majority of the farmers in developing and low income countries are poor and they don't have enough opportunities and access to use such type of technology without cooperation. For this reason, it may happen that the agricultural season may go away but the poor farmers don't get their appropriate production technologies if the government or respective authorities don't take proper care about this matter. Moreover, there is a great concern about the contamination of crops from a plot of GM crop to a plot of non GM crop due to cross pollination. This type of ideas can create due to the lack of appropriate research based knowledge in the field of biotechnology. GM crops technology and its research activities are not well developed in many developing countries.

There may be a few ecological and health related problems associated with GM crop technology as researchers like Altieri (2001) and Friends of the Earth (2008) argue that environmental problem, health risks and the adverse social implications are the fear of GM crop technology. In these circumstances, it is very important to identify what kind of environmental and health risks associated with it and how much the depth of that problem; is it a serious or moderate or minor problem? So that people can aware from it. Application of this technology can undermine the traditional knowledge systems in developing countries as Sharma (2004) argue that there may be a problem of monopoly seed markets and exploitation of landless, marginal and small-scale farmers in low income developing countries due to increasing privatization of crop expansion research and propagation of intellectual property rights.

\section{Conclusion and Recommendations}

The above facts and figures find a lot of discussions about biotechnology as well as GMOs. Several scholars argue in favor of GMOs (e.g., Albrecht, 2002; Bouis, 2004; Gavrilescu and Chisti, 2005; Qaim, 2009; Brookes and Barfoot, 2009) and a quite number of scholars argue against GMOs (e.g., Altieri, 2001; Sharma, 2004; Friends of the Earth, 2008). Hence, it is not quite easy to argue that biotechnology and GM crop technology may ensure the sustainable agriculture or not, but somehow GMOs can perhaps help to increase crop production and that can contribute to feed the growing population in the next decade.

GM (Genetically Modified) crop technology may possibly be helpful to increase productivity in agriculture and in reducing seasonal fluctuations in agricultural productions against ever increasing demand for food and other agricultural products, global climatic changes, scarcities in natural resources, etc. GM crops may reduce the environmental and health related problems by reducing the use of chemical pesticides and insecticides. Qaim (2009) argue that both farmers and consumers can be benefitted from GM crops and that may indicate a large scale welfare gains and in some cases the benefit of the farmers of developing countries are more than that of developed countries. Moreover, it can contribute to increased rural farm income in some developing countries. GM crops with higher micro-nutrient contents can help in reducing the nutrient deficiencies among the hard-core poor (Swaminathan, 2010). In spite of these potentials, public attitudes regarding the use of GM crops are controversial and new risks are related to bio-safety, food safety, and labeling regulations. In addition, if this technology disrupts the traditional farming systems, it may be inappropriate for small-scale farmers in developing countries.

There is no single bullet solution for solving all the problems of developing countries but GMOs can contribute in the reduction of food scarcity and sustainable growth in agricultural sector (Altieri and Nicholls, 2005). For this reason, more public support is necessary for the development of biotechnology 
as well as GM crop technology all around the world. However, strong political decision is necessary to opt for GMOs. Many countries e.g., India, USA, Brazil etc., have introduced GMOs despite the criticisms against GMOs among the stakeholders. Hence, more and more scientific investigations are necessary to achieve the significant trust from the general people and thus can ensure the true facts of this technology in the path of sustainable development in crop production.

\section{References}

Albrecht, J. 2002. Biotechnology and micronutrient deficiencies in developing countries: A comparative economic assessment of golden rice. Paper presented at the 6th ICABR conference, Ravello, Italy, July 11-14.

Altieri, M.A. and Nicholls, C.I. 2005. Agro-ecology and the search for a truly sustainable agriculture. Basic textbook for environmental training. United Nations Environment Program, Environmental Training Network for Latin America and the Caribbean.

Altieri, M.A. 2001. Genetic engineering in agriculture: The myths, environmental risks and alternatives. Oakland, CA: Food First.

Altieri, M. 1995. Agro-ecology: The science of sustainable agriculture. West-view Press, New York.

Bouis, H. 2004. Hidden hunger: The role of nutrition, fortification, and bio-fortification. Presented at world food prize international symposium, October 14-15, Des Moines, IA.

Bouis, H. 2007. The potential of genetically modified food crops to improve human nutrition in developing countries. Journal of Development Studies 43:79-96.

Brookes, G. and Barfoot, P. 2009. Global impact of biotech crops: Income and production effects, 1996-2007. AgBioForum 12(2): 184-208.

Burachik, M. 2010. Experience from use of GMOs in Argentinian agriculture, economy and environment. New Biotechnology 27: 588-592.

Carpenter, E.J. 2011. "Impacts of GM crops on biodiversity". GM Crops 2: 1-17.

Fan, S., Chan-Kang, C., Qian, K. and Krishnaiah, K. 2005. National and international agricultural research and rural poverty: the case of rice research in India and China. Agricultural Economics 33: 369-79.

FAO, 2004. Agricultural biotechnology: Meeting the needs of the poor? The State of Food and Agriculture 2003-04. Food and Agriculture Organization of the United Nations: Rome, 2004

Friends of the Earth, 2008. Who benefits from GM crops? The rise in pesticide use. Agriculture and Food Issue 112. Amsterdam: Friends Earth International.

Gavrilescu, M. and Chisti, Y. 2005. Biotechnology - A sustainable alternative for chemical industry. Biotechnology Advances 23 : 471-499.

Giuffre, L. et al. 2006. Multivariate evaluation by quality indicators of no-tillage system in Argiudolls of rolling pampa (Argentina). Biology and Fertility of Soils 42: 556-560.

Graff, G., Roland-Holst, D. and Zilberman, D. 2006. Agricultural biotechnology and poverty reduction in low-income countries. World Development 34: 1430-1445.

Hazell, P. and Ramasamy, C. 1991. The green revolution reconsidered: The impact of high-yielding rice varieties in south India. Baltimore, MD: Johns Hopkins University Press.

Herring, R. J. 2007. The genomics revolution and development studies: Science, poverty and politics. Journal of Development Studies 43:1-30.

Huang, J., Hu, R., Rozelle, S. and Pray, C. 2005. Insect resistant GM rice in farmers' fields: Assessing productivity and health effects in China. Science 308: 688-690.

Huylenbroeck, V.G. and Durand, G. 2003. Multi-functional agriculture: A new paradigm for European agriculture and rural development. UK. Aldershot, Ashgate.

James, C. 2011. Global status of commercialized Biotech/GM crops: 2011. The International Service for the Acquisition of Agribiotech Applications (ISAAA) Brief No.: 43. ISAAA: Ithaca, NY.

James, C. 2009. Global status of commercialized Biotech/GM crops: 2008. The International Service for the Acquisition of Agribiotech Applications (ISAAA) Brief No.: 41. ISAAA: Ithaca, NY.

Juma, C. 2005. Going for growth: Science, technology and innovation in Africa. The Smith Institute, London, UK.

Losey, J.E., Rayor, L.S. and Carter, M.E. 1999. Transgenic pollen harms monarch larvae. Nature 399: 214.

Micucci, F.G. and Taboada, M.A. 2006. Soil physical properties and soybean (Glycine max, Merrill) root abundance in conventionally and zero-tilled soils in the humid pampas of Argentina. Soil Tillage Research 86: 152-162.

Miller, H.I. and Conko, G. 2004. The frankenfood myth: How protest and politics threaten the biotech revolution. Westport, CT: Praeger. 
Nyange1, N.E. et al. 2011. Biotechnology for sustainable agriculture, food security and poverty reduction in Africa. Access Not Excess ed. Charles Pasternak. Chapter 3, pages 19-30.

Paarlberg, R.L. 2008. Starved for science: How biotechnology is being kept out of Africa. Cambridge, MA: Harvard University Press.

Pinstrup-Andersen, P. and Schioler, E. 2001. Seeds of contention: World hunger and the global controversy over GM crops. Baltimore, MD: Johns Hopkins University Press.

Pray C., Huang, J., Hu, R. and Rozelle, S. 2002. Five years of Bt cotton in China: The benefits continue. The Plant Journal 3: 423430.

Qaim, M. and De-Janvry, A. 2005. Bt cotton and pesticide use in Argentina: economic and environmental effects. Environment Development Economics 10: 179-200.

Qaim, M. and Traxler, G. 2005. Roundup ready soybeans in Argentina: farm level and aggregated welfare effects. Agricultural Economics 32: 73-86.

Qaim, M. 2009. The economics of genetically modified crops. Annual Review Resource Economics 1: 665-694.

Qaim, M. 2010. Benefits of genetically modified crops for the poor: household income, nutrition, and health. New Biotechnology 27 : 552-557.

Sharma, D. 2004. GM food and hunger: A view from the South. New Delhi: Forum Biotechnology Food Security.

Shiva, V. and Bedi, G. 2002. Sustainable agriculture and food security: The impact of globalization. Sage Publications Pvt. Ltd, New York.

Swaminathan, S.M. 2010. Achieving food security in times of crisis. New Biotechnology 27: 454-460.

Unnevehr, L., Pray, C. and Paarlberg, R. 2007. Addressing micronutrient deficiencies: alternative interventions and technologies. AgBioForum 10: 124-134. 